\title{
Interpreting the Anomalous: Finding Meaning in Out-of-Body and Near-Death
}

\section{Experiences}

\begin{abstract}
Much contemporary research on anomalous experiences has been focused on issues of confirming the authenticity of the phenomena, or to determine the underlying processes by which these phenomena may manifest themselves. This research has largely been nomothetic in nature relying mainly on laboratory experiments and/or questionnaire surveys. Yet, traditionally, there exists a third strand of exploration in this field of study-phenomenological research-which in recent times has been somewhat overlooked in this field of work. In an attempt to redress this shortcoming, the authors propose the use of Interpretative Phenomenological Analysis (IPA) to research anomalous experience. IPA possesses strong theoretical and philosophical underpinnings and a focus on describing and interpreting the process, intricacy and novelty of personal experience. The authors argue therefore that IPA appears ideally suited as a method of qualitative investigation to address important fundamental research questions posed by the study of anomalous experiences. By examining in-depth the experience and meaning of these critical life events, IPA research findings can better furnish psychologists and health care professionals with information to further appreciate and understand their clients' experiences and to help them with any potential personality transformations or psycho-spiritual crises that may arise after the event.
\end{abstract}

Key words: Anomalous experiences; Interpretative Phenomenological Analysis; qualitative methodology; Outof-Body Experiences, Near-Death Experiences 


\section{What Are 'Anomalous Experiences'?}

Paranormal phenomena have long been a source of interest and debate for society as well as areas of research interest in psychology (Cardeña, Lynn, \& Krippner, 2000; Inglis, 1992; Wooffitt, 1992). As with many topics in psychology, defining an area of interest can prove problematic. Conceptually, there exists several terms that describe the study of paranormal phenomena (e.g. parapsychology, psi or psychical research), each purporting to embrace a slightly different range of topics and approaches within their spheres of study. ${ }^{1}$

More recently the term 'anomalous experience' has become increasingly used among researchers interested in the study of the paranormal. Anomalous experiences have been defined by Cardeña et al (2000, p. 4) as "uncommon experience[s]...[or encounters] that, although...experienced by a substantial amount of the population...[are] assumed to deviate from ordinary experiences or from the usually accepted explanations of reality”. From this definition, anomalous experiences can be conceived of more broadly as encompassing topics such as extra-sensory perception (ESP), psychokinesis (PK), out-of-body and near-death experiences, altered states of consciousness, hypnosis, religious, mystical or spiritual experiences, alien abduction experiences (AAEs), dissociative phenomena, and hypnagogic and hypnopompic hallucinations. This list is by no means definitive and the true range of anomalous experiences is difficult to classify given their diversity (Castro, 2005).

In this paper, we prefer to use the term 'anomalous experience'2 rather than 'paranormal' or 'parapsychological' due to its overall inclusiveness of a broader range of phenomena conducive to psychological inquiry. We feel this is important as, given the differences in scope, nature and focus of investigation suggested by the terms above, it is probable that the conceptions of what constitutes a 'paranormal' happening will vary between experients and non-experients and even between different professionals. Moreover, the word 'experience' draws into focus the personal nature of these occurrences. That an out-of-body experience 
does occur is without doubt. Whether or not the event is a literal separation of something from the physical body or an elaborate hallucination is a matter for further investigation. The way in which an experient will interpret and draw meaning from the event will be dependent, in part, upon if that person believes they have left their body or not. What then may be of great concern to the experient (and researcher) is the 'emergence' of the experience into their consciousness. How did the phenomenon initially present itself? What did it feel like? Irwin and Watt (2007a) suggest this concern with perceptions is fundamental in the scientific investigation of anomalous experiences, and is reflected in their definition of parapsychology as, "the study of experiences having the appearance of being in principle outside the realm of human capabilities as conceived by conventional scientists" (p.3).

Taking the above points-experience, belief, appearance-into consideration, in the remainder of this paper we will argue that the study of anomalous experiences would be further enhanced if researched using a qualitative, idiographic approach such as Interpretative Phenomenological Analysis (IPA). IPA is concerned with the investigation of lived experience. It views experience, not solely as a possession of a person, but more as a correlational relationship between the person's consciousness and the phenomenon itself (Langdridge, 2007). Phenomenologically speaking, Husserl (1931) termed this 'intentionality'; the correlation between that which is being experienced (the noema or noematic correlate) and how it is being experienced (noesis or the noetic correlate).

In taking this view, IPA then assumes that a person's experiences can be accessed and understood through an exploration of the meanings they apportion to those experiences. In the following sections we will focus on describing what IPA is, how it fits into the pantheon of current qualitative approaches and what makes IPA particularly suitable for the study of anomalous experiences. We will illustrate our arguments with empirical examples of how we 
have used IPA to explore the lived experiences of people who have had out-of-body and near-death experiences.

\section{Interpretative Phenomenological Analysis and its Relevance to the Study of Anomalous}

\section{Experiences}

Much of the contemporary research conducted on anomalous experiences has been focused on issues concerning either the veridicality of the phenomena, or to determine more precisely the underlying processes by which these phenomena may manifest themselves. This research agenda has produced a wealth of creditable studies of a mostly nomothetic nature using laboratory experiments (e.g. Bem \& Honorton, 1994) and/or questionnaire surveys (e.g. Kennedy \& Kanthamani, 1995).

Yet, historically and traditionally, there exists a third strand of exploration in this field of study-phenomenological research-which in recent times has been somewhat overlooked, one might say, to the detriment of understanding the psychological life of the person having such experiences (Irwin \& Watt, 2007a). There are, of course, several notable examples of this kind of work, for instance, Hanson and Klimo's (1998) study of synchronicity, ${ }^{3}$ Barrett's (1996) work on channeling, ${ }^{4}$ Heath's $(1999 ; 2000)$ examination of PK experiences, the research conducted on ESP experiences by Reed (1995; 1996), and the phenomenological work of Valle (e.g. , 1998). However, it remains the case that compared to the scale and variety of the field of study, phenomenologically-based research is still a neglected approach in this area. In an attempt to redress this shortcoming, we discuss Interpretative Phenomenological Analysis (IPA) here as a relatively new qualitative method for investigating anomalous experiences. IPA differs in relation to other phenomenological approaches used in this field of study in that it takes its influence from the broader body of phenomenology, rather than endorsing one specific form of it (Smith, Flowers \& Larkin, 
hermeneutic approach in their work). Moreover, whilst most phenomenological methods are purely descriptive in their approach, IPA is delineated by its interpretative element. IPA also embraces the idiographic traditions of examining convergence and divergence across cases, unlike some phenomenological traditions which seek to build up common accounts of people's experiences with the aim of describing a generalized structure of the phenomenon under scrutiny (Langdridge, 2007).

Theoretically and philosophically, IPA is founded on a blend of three main philosophies of knowledge: phenomenology, hermeneutics and idiography (Smith, Flowers, \& Larkin, 2009).

IPA is principally phenomenological in that it seeks to obtain and honor a person's experiences, understandings, perceptions and accounts (Reid, Flowers, \& Larkin, 2005). There is no attempt to construct an objective 'truth' about an experience, but there is an appreciation that experiences are 'meaning-full' for a person. For this reason IPA is more concerned with the subjective account and meaning of an experience (Brocki \& Wearden, 2006).

However, IPA also acknowledges that in order to reach a deeper understanding of ourselves and our world, it is important to consider how a person interprets their world, both individually and socially. In attempting to gain access to another person's world IPA recognizes that "access depends on and is complicated by the researcher's own conceptions...required in order to make sense of that other personal world through a process of interpretative activity" (Smith, Jarman, \& Osborn, 1999, pp. 218-219). IPA then positions itself 'centre-ground' between purely realist and social constructionist approaches (Smith, Flowers, \& Larkin, 2009). It aims to achieve this position by balancing both the hermeneutics of empathy and critique by attempting to view a participant's experience through their eyesthe 'insider's perspective (Conrad, 1987)-while concurrently trying to maintain a critical 
distance. This critical perspective, however, is not one of suspicion, rather it emphasizes the role of the researcher as an active player in the interpretation process, what Smith (1996) refers to as the 'double hermeneutic'. Smith conceptualizes the double hermeneutic as thus; a single hermeneutic refers to a participant trying to make sense of their lifeworld, the double hermeneutic involves the researcher trying to make sense of the participant trying to make sense of their lifeworld. From this perspective, IPA is then both descriptive and interpretative as it holds that no phenomenon can be perceived without some form of interpretation taking place.

IPA takes an idiographic approach to the study of the human condition in that its focus is chiefly concerned with the painstaking, detailed analysis of specific cases. Human experience is viewed as "uniquely embodied, situated and perspectival" (Smith, Flowers, \& Larkin, 2009, p. 29) while at the same time acknowledging that people are rooted in the real world, and as such are relational to things, events and others.

Where IPA has perhaps taken its most controversial direction is in its concern with the cognitions of the person. Willig (2001) and Langdridge (2007) have been critical of this concern, viewing it as incompatible with the fundamentals of phenomenology; in particular phenomenology's rejection of Cartesian dualism. However, the interest IPA has with cognition is based on a broader conception than is perhaps currently held by contemporary cognitive psychology. In attempting to clarify this issue, Smith, Flowers and Larkin (2009) have expanded their vision of the phenomenological 'natural attitude' to incorporate "both pre-reflective and reflective activity" (p. 188). They suggest that, rather than being a dichotomous activity, reflective activity is carried out on multiple layers, from 'pre-reflective reflexivity' to 'deliberately controlled reflection', with each layer characterized by an enhanced degree of awareness (see Smith, Flowers, \& Larkin, ibid, pp187-194, for a more complete account). In carrying out IPA, therefore, the researcher is confronted with the task 
of disentangling a 'chain of connection' between what a person might be thinking (cognizing), what they are saying about those thoughts (narrative account) and what they are doing about it (behaviour). In this sense IPA has aligned itself with Bruner's (1990) original "vision of cognitive psychology as a science of meaning and meaning-making rather than a science of information processing" (Smith \& Eatough, 2006, p. 325).

Given what we have outlined above, we would like to close this section by emphasizing why we think IPA would be suitable to use as a method of qualitative investigation for the study of anomalous experiences.

Smith and Osborn (2003, p. 53) have described IPA as "especially useful when one is concerned with complexity, process or novelty". This would seem to fit well with the three central concerns of anomalistic experiential research-authenticity, underlying process and phenomenology (Braud, 2004; Irwin \& Watt, 2007a). For example, IPA can help address experiential research questions, such as, what is the lived experience of having synesthesia? Or indeed, further light may be shed on more process-oriented matters, such as, what do participants say facilitates or inhibits the control of their out-of-body experiences?

Conceptual inquiries may also be considered, such as, how is the metaphor of 'the path' used by those seeking spiritual growth and development? Allied to conceptualization is theorizing about the findings of research. Questioning an experience from a theoretical perspective may help with the generation of future research hypotheses or aid in exposing underlying processes. Although principally an idiographic method of inquiry, IPA also recognizes the importance of theory. IPA researchers have addressed the issue of when and where to draw upon theory in the research process without contravening the inductive nature and spirit of the method in several ways (Storey, 2007). The first involves bringing theory into play during the post-hoc stages of analysis, once the majority of the preliminary descriptive coding has been completed and more conceptual and linguistic coding is underway. This retains the 
focus on what the participant is saying in their own words about their experiences, without imposing any particular theory onto the data (e.g. Flowers, Smith, Sheeran, \& Beail, 1997). Vignoles, Chryssochoou and Breakwell (2004) have adopted a slightly different approach this by choosing in advance which theoretical models they wished to use to interpret the data. Chin, Hayward, \& Drinnan (2009) varied this approach again by specifying one theoretical framework prior to analysis and using that to inform the analysis, rather than employing it in a theory testing fashion.

One criticism that has been leveled at research into anomalous experiences is that studies be as robust as possible to potential biases brought about by the beliefs of the researchers themselves (Druckman \& Swets, 1988) (but see also a rejoinder to this by Palmer, Honorton, \& Utts, 1988). Irwin and Watt (2007a) have discussed this issue, noting that the subject matter itself "tends to evoke extreme reactions in people, either of uncritical, soft-minded gullibility in the paranormal or of unyielding, closed-minded skepticism” (p. 2). Drawing upon its phenomenological roots, IPA encourages its practitioners to suspend their preexisting assumptions, beliefs and knowledge towards the experience under consideration (often called 'bracketing'). In so doing, the researcher takes a reflexive turn in which they bring in to focus their own presumptions and biases and then put these to ones side in order to view the phenomenon from a fresh perspective (Langdridge, 2007). Although, in practice, most researchers will acknowledge that this is very difficult to do.

Anomalous experiences are often novel events that are a defining part of the experient's life, and as such the experient will cognize about them, talk about them and their behaviour can be affected permanently afterwards. Fittingly, the personal biographical framework in which IPA works, which is not traditionally a concern of phenomenology, as well as its cognitive focus, is ideally suited to investigate the social, psychological, affective and temporal factors that may dominate a person's experiential world prior to, during and beyond 
their encounter with events they may perceive as 'uncommon'. Furthermore, several authors (e.g. Braud, 1993, 2004; Brown \& White, 1997; White, 1997) have called for more research on the significance and impact anomalous experiences have on those who have them. This research can be carried out independently of whether or not the anomalous experience in question has exhibited externally corroborated veridical elements (Braud, 2004; Irwin \& Watt, 2007a). Being qualitative in nature, and thereby being able to produce detailed, substantially descriptive and interpretative accounts of anomalous experience, IPA gives the anomalistic psychological researcher a unique approach for understanding how experients find meaning in and make sense of their experiences.

\section{Examples of Interpretative Phenomenological Analysis as Applied to the Study of Out- of-Body and Near-Death Experiences}

In this section, we will illustrate some of the features of IPA that we have discussed above with a selection of our recent empirical work conducted on the topic of out-of-body and neardeath experiences. Before we do that, we must first define what these two anomalous phenomena are.

The out-of-body experience (OBE) has been defined by Irwin and Watt (2007b, p. 173) as a phenomenon whereby "the centre of consciousness appears to the experient to occupy temporarily a position which is spatially remote from his/her body" and has been a research topic for psychologists for over 100 years (Alvarado, 1992). Phenomenologically, the OBE is characterized by a multiplicity of features, but those most commonly reported in the literature are: a floating sensation, seeing the physical body from a remote point in space, and the impression of travelling to distant locations (Alvarado, 2000). OBEs have been reported to occur under a variety of different circumstances, such as; happening spontaneously (Blackmore, 1986); during periods of illness or stress (Palmer, 1978); via voluntary 
induction, following techniques suggested by Monroe (1971) for example; under hypnosis (Cardeña, 1988); whilst under the influence of alcohol or drugs (Tart, 1971); whilst meditating (Kohr, 1980), and as part of a near-death experience (Ring, 1980).

The majority of previous research on OBEs has aimed to 'profile' people who have OBEs; in order to describe their personality, or to predict what kind of personality would be most likely to have an OBE. Such studies have found that people who have had out-of body experiences (OBErs) score higher on measures of dissociation, especially somatoform dissociation (Irwin, 2000, Murray \& Fox, 2005), fantasy proneness (Gow et al., 2004), paranormal belief (Tobacyk \& Mitchell, 1987), and display a propensity to become more psychologically absorbed (Myers, Austrin, Grisso \& Nickeson, 1983) than non-OBErs.

The near-death experience (NDE) has been defined by Greyson (1994, p. 460) as "a profound subjective event with transcendental or mystical elements that many people experience on the threshold of death". Although reports of NDEs have appeared throughout recorded human history (e.g. Walker \& Serdahely, 1990), they were first brought popular and increased academic attention in the mid-1970's with the publication of Raymond Moody's (1975) book, 'Life after Life'.

The majority of studies conducted on NDEs have profiled the experient as a healthy, welladjusted individual (Greyson, 2000), and delineated the occurrence of the NDE as one free from demographic differentiation (Ring, 1980) and as a mostly a positive, life-affirming experience (Ring, 1993) that can happen at any time during the lifespan (Atwater, 2003). Although not all NDEs are pleasant journeys; some have been reported to be quite frightening (Greyson \& Bush, 1992).

\section{Background to the Research}


Before presenting any of the examples of IPA that we have used, it is necessary to give some context to the research that uncovered these findings.

Previous survey research by the authors (Murray, Fox, \& Wilde, 2006) investigated OBE incidence under five different circumstances; OBEs occurring spontaneously, whilst meditating, whilst ingesting alcohol or drugs (either for medicinal purposes or recreationally), whilst under perceived or real physical or psychological threat (but not near-death), and as part of a NDE. As part of that survey, OBErs supplied accounts of their OBEs. An analysis of those accounts directed the researchers to consider the OBE more broadly as a life-event when designing the study from which the following data extracts are culled.

The study employed a qualitative approach using IPA. Fifteen participants were recruited corresponding to the five groups of OBE occurrence described above, with three participants in each group. The sample consisted of five males and ten females with an average age of 43 years. Data was collected through the use of face-to-face, semi-structured interviews which lasted approximately one hour and were digitally audio-recorded and fully transcribed for analysis purposes. ${ }^{5}$

The examples presented herein are excerpts taken from analysis of transcripts with participants who have experienced an OBE spontaneously, whilst meditating, or as part of an NDE. It is impossible to produce a full account here of all the research findings from these three groups. Instead, we present a selection of material that is illustrative of three themes that were common across many of the interviews. ${ }^{6}$ The themes illustrated here are: (1) Safe secrets and dirty truths: the art and practice of disclosing an anomalous experience; (2) Being, growing and 'dying': integrating an anomalous experience and the transformative effects on the self; and (3) The embodied nature of anomalous experiences. 
This theme describes the efforts participants made to share their experiences with other people as part of an attempt to reach some understanding about them. However, most found that knowing when, where and with whom to disclose information about having had an OBE could be very challenging. For example, Mark and John reported having had spontaneous OBEs. Each had a strong wish to talk about their OBEs with other people but differed in their ability to fulfil this wish. Mark's attempts at disclosure to his parents had met with some dismissiveness, particularly from his father. This experience had helped to galvanize a longterm personal inhibition about talking further about his OBEs as illustrated in this extract:

I think I made a mistake sometime by discussin' in the workplace...People just tend to dismiss it an' go, "What are y'on about?"...it's probably because they're not really interested...But like I say, I don't think the workplace is the right place to discuss it...it's quite a clumsy thing to do really.

Mark's use of the word 'clumsy' in this extract is reveals his perception of the awkward nature of his social encounters with people who did not believe his story. By contrast, John felt inhibited from the outset about discussing his experiences:

It's the sort of thing I would want to share, but I'd only tell select people that I could trust, they wouldn't laugh at me and that sort of thing.

In this extract, John reveals that he knows how his story might be perceived and is strategizing about how best to satisfy his need to share the experience with the perceived costs in terms of the reactions he may face in return. This tactic was observed in other interviewees. For example, Patricia-who had her OBEs whilst meditating-suspected that 
others would not see her OBEs as authentic and seemed cautious about avoiding disbelief or ridicule:

\begin{abstract}
There's no point really spoiling these experiences for myself 'cos I didn't want to have to sort of justify them or explain them...that might spoil my memory of them...I didn't want them sort of dirtied in any way by people scoffing at them or laughing at them...so I thought, oh, well, best not really...it's sort of better to keep it as a safe secret than a dirty truth or something.
\end{abstract}

What is most revealing in this passage is the high value Patricia (and others we interviewed) placed on her OBEs. The experience and the memories of it are something to be treasured and protected. Also emergent in this passage is the notion that her OBEs would have to be justified or explained, suggesting that the experience would not be accessible or easily understood by other people. This is something Patricia is keen to avoid. Her OBEs are precious to her and she feels that having to defend them to others would ruin her memories of them and might even prevent her having more in the future.

These perceptions raise important issues for how our society views anomalous experiences. Historically, OBEs have been discussed in connection with hallucinations (e.g. Blackmore, 1984) and mental illnesses (e.g. Rawciffe, 1959) with little direct evidence to perpetuate such assumptions. However, the perception of a mental disorder can lead to stigmatization and discrimination, personally, institutionally or structurally, or through social psychological processes which engage the perceptions of the person being stigmatized (e.g. schizophrenia Dinos, Stevens, Serfaty, Weich, \& King, 2004). Whilst we found no accounts of direct discrimination, the views expressed above, particularly from Mark, do suggest encounters with others who perceived a person who has OBEs as having something 'wrong' with them. This can be further compounded depending upon the social context in which the disclosure is embedded. For example, earlier, we saw the difficulties Mark faced in disclosing 
his OBEs in his workplace. Later in his interview he described how he received "negative feedback" with some people suggesting he had "made it up" or was "telling lies". Similarly, Cindy-another respondent who had a spontaneous OBE-recalled the reactions she encountered from hospital staff when she told them of her experience: "they looked at you like...they thought I was mad".

These and other similar reactions have important implications for the identity of OBErs. Human beings are individuals immersed in a particular culture which is created and sustained publicly through language and communication, in particular through narrative and storytelling. As Bruner (1990, pp.52-55) notes, “[narrative] deals with the stuff of human action and human intentionality. It mediates between the canonical world of culture and the more idiosyncratic world of beliefs, desires, and hopes...what, broadly, might be called the 'organization of experience'”. Although IPA's main concerns are with individual experience, it also acknowledges that experience is bounded within culture and language, and in conducting IPA, the researcher inevitably hears the stories of participants in the process of 'organising' their own experiences into a communicable, interpretable and understandable whole. With OBErs, this may be the first time they have had the chance to discuss in depth their OBEs (as John and Patricia revealed in their interviews). This can be somewhat 'therapeutic' for the participant. The positive effects of successful sharing and disclosure of experiences such as OBEs have been acknowledged by Palmer and Braud (2002), who found that scores on measures of disclosure of Exceptional Human Experiences (EHEs) positively correlated with measures of personal and existential meaning in life and psychological wellbeing. There was also a negative correlation with stress related physical and psychological illnesses. 
Being, Growing and 'Dying': Integrating an Anomalous Experience and the Transformative

\section{Effects on the Self}

The second theme we present relates to the impact our participants' anomalous experiences had upon their sense of self, and is concerned with the potential for the experience to function as an adaptive form of behaviour. In this theme we will draw upon illustrations from interviews from one of our NDE participants.

Jane was a married, twenty-something young woman who had few aspirations beyond settling down into a family way of life. During an operation in hospital for a burst stomach she had an NDE. Her NDE was characterized by very strong emotions; fear, anger, anxiety, isolation and remorse. These emotions were set against a background of several distinct motifs, the most powerful of which was Jane's descent in to a dark and lonely void. Whilst in this place she reflected upon her life, her relationships with her friends and parents, and the times she had said and done bad things in her life. This motif was characterized by crushing feelings of inadequacy. Amidst this heavy, lonely feeling she heard a voice say to her, "don't be too hard on yourself", and at that point she returned to her body and awoke from the operation. Jane felt that the NDE changed her life and development as a human being considerably. As the days and weeks passed, she began to notice alterations in her beliefs and attitudes. These were underpinned by some major life changes as she found herself gradually becoming absorbed in developing herself personally and spiritually. As part of her sensemaking processes, interpersonal relationships became of primary importance to her:

I ended up accepting myself for the person that I was... knowing that I was loved and loveable...I've never really succeeded because my, actually my friends were pretty screwed up people...it's just accepting them and accepting the best possible solutions as far as day-to-day relationships went. 
Signs of the influence of Jane's NDE began with a general feeling of having been exposed to information which necessitated a re-alignment of her personal beliefs and values about such issues as life after death, religion and her relationships with her friends/family and with God:

It was such a big change for me because I suddenly had to think about my, what my beliefs were suddenly again.

Jane perceived her NDE as a new beginning and was no longer afraid of dying. She confessed it was hard to say what influences could be attributed directly to the NDE, however, she did not think she would have become a counsellor without having had that experience.

In considering IPA for a study of this kind, we wanted a method which would take seriously the experiential claims of the near-death experient and that would be sensitive enough to uncover the meaning the experients attribute to their NDE. As noted earlier, IPA concerns itself with addressing issues regarding changes in a person's identity especially those associated with major life transitions (e.g. Smith, 1999). Corbett (1996) has proposed that the meaning of an event has a form of "dispositional power" over how a person will think and behave following that event. Findings from this study have shown that NDEs can be fruitfully regarded as critical life events (Dougherty, 1990) in terms of the transformation of person's sense of self, identity, and their views towards relationships and general life directions. This 'dispositional power' of critical life events has been previously acknowledged by various authors (e.g. Baltes \& Danish, 1980). 
Embodiment has typically been a major consideration of phenomenology (e.g. MerleauPonty, 1962). More recently, it has enjoyed a resurgence of interest from psychologists (e.g. Finlay \& Langdridge, 2006). Yet, the importance and role of the body has remained relatively untouched in the field of anomalous experiences (but see Murray \& Fox, 2005). In our third theme, we look briefly at embodiment issues in relation to OBEs occurring under meditative conditions. In particular, we examine how some participants described high degrees of control over their OBEs and viewed these experiences as learned, embodied skills.

Participants who had their OBEs whilst meditating displayed a strong desire for control, usually in relation to some form of unfulfilled needs in their lives. One of these participants, Patricia, revealed how her need for control manifested in both her personal and professional life. Patricia is a professional dancer and choreographer. Her mind and body are the tools of her trade. She explained early in the interview how she had used her OBEs to fulfil a need to overcome her fear of losing connection with loved ones and friends. Unexpectedly, she talked about how she appeared to have embodied her OBEs also; essentially viewing them as a tool she could use to help solve certain problems in her life. She elaborated on this, describing times when these emotions became too much for her leading to a strong desire to leave her body and an attempt to re-connect with those she missed:

\footnotetext{
I remember...feeling really, really homesick, and sort of having a meditation...I think I was probably trying to get out of my body... and trying to get further and further away and trying [to] imagine where all my friends and family were...looking for people...like needing to find friends.
}

Patricia also mentioned how her first OBEs had happened as a child and then stopped before reappearing again in adulthood: 
For me it felt like something that I already knew how to do as a child, it was something that, that was quite familiar to me, it was like a skill I'd forgotten how to do, and this [the meditation] had helped remind me how to do it.

The roots of her openness to experiencing OB states seem to have been founded in her childhood. When learning to meditate, she already had the cognitive skills from previous OBEs, and bodily knowledge from her dancing, to take advantage of the experience and use it as an extension of her self. This skill acquisition and development manifested in a great degree of control in entering and navigating the out-of-body environment:

[Talking about onset sensations] The energy...the only way you can sort of do it is sort of through imagery really...it's kind of like a...fountain or something, and it sort of goes up through layers, levels through your body, I've read stuff about chakras and stuff like that, I don't necessarily believe it but I know what things feel like...it sort of goes through and up and into different levels and it sort of hits sort of target points and it can either stop or build up speed...if it comes out the top you really have no control over that, you can’t make it happen...if you imagine there's like a push of water up and sort of bubbles at the top, well you're sort of sat on the top...but it's kind of coming from your own energy, really...whereas... with meditation you can almost track it, you're a bit more in control of it somehow... [and later when in the out-of-body state]...I saw myself...seeing my room from above and then the red roof of my block of flats and the street outside... and seeing like the [town] outskirts... and sort of being able to say, ok, that must be Warsaw over there, that must be Krakow down there, that must be Berlin over there...ok that's the Baltic, almost like being in an aircraft, I suppose...focusing in and going down and trying to sort of see streets and identify places where I used to live or where people would be.

This last quote is a good example of the sizeable, thick description IPA interviews can yield. Several aspects of Patricia's self emerge from these extracts. Phenomenologically speaking, Mauss (1950) as cited in Csordas (1993, p. 139) has underlined the function of 
cognitive processes such as attention and imagination in the acquisition and perfection of physical skills (e.g. sports athletes). Csordas (ibid) coined the term "somatic modes of attention" and defined this as "culturally elaborated ways of attending to and with one's body in surroundings that include the embodied presence of others" (p. 138) that could be extended to altered states of consciousness, potentially invoked by meditation and OBEs.

Bruner (1990) viewed the body as a biological assemblage of restraints and possibilities, the meanings of which are derived via an individual's immersion with their cultural world. Whereas Husserl (1931) had previously described this relationship between consciousness and the world as 'intentionality', Merleau-Ponty (1962) preferred the term 'body-subject' to stress the intertwined nature of an individual's physical and mental aspects of existence. For Merleau-Ponty, intentionality is the process by which "consciousness projects itself into the physical world and has a body, as it projects into a cultural world and has its habits" (1962, p.137). The term embodiment herein refers to the psychological sense of being in the physical body but also having the potential to transcend its physical limits. In the specific context of the data presented here, this term also refers to the linking of experiential episodes beyond the physical with the daily experience of being-in-the-world. ${ }^{7}$

Patricia's description of her progressive embodiment of her OBEs such that it becomes a skill is reminiscent of Merleau-Ponty's (1962) concepts of 'intentional arc' and 'maximum grip'. Merleau-Ponty suggested that intentionality starts from a position within the body and extends outward, engaging the world around it. In the process skills are acquired by interacting with objects and situations. This further leads to the concept of maximum grip-to achieve an increasingly superior grasp of lived situations. The cognitive skills depicted in Patricia's account of her goal directed, way finding behaviour when out of her body are also evocative of Anderson's (2003, p. 105) description of how a person cognitively navigates their environs. 
The notion that the OBE could be a 'tool' in order to extend one's sense of self (Hall, 1969) and developed is consistent with the more pragmatic purposes sought in meditation (e.g. combating stress). That some people may be better at this than others suggests that this ability could be fruitfully viewed as idiosyncratic personality variable. Evidence from meditation research has found that a person's ability to intentionally regulate their attention when meditating depended more on their in-built capacity for absorption than did the length of time they had been practicing the technique (Hoelzel \& Ott, 2006). Additionally, Davidson, Goleman and Schwartz (1984) found that absorption was higher and anxiety lower in long-term meditators than it was in their beginner and control group members, suggesting a training effect with prolonged practice. Alvarado (2000) has suggested that one possible reason why people have multiple OBEs is that, after their first OBE, they become more skilful at identifying the onset of subsequent OBEs and thus develop greater cognitive abilities to aid the progression of the OBE when it starts.

\section{Conclusions}

In this paper we have argued for the use of Interpretative Phenomenological Analysis (IPA) as an approach for investigating anomalous experiences. In our considerations we have noted the relative lack of phenomenologically-based qualitative work that has been carried out so far in this field. In attempting to show the relevance of IPA to the study of anomalous experiences, we have highlighted how the robust, broad ranging theoretical and philosophical underpinnings of the approach compliment certain key issues of anomalistic experiential research. We have also emphasized the idiographic nature of the approach, which focuses on the meaning and impact such experiences can have on people and the meanings and interpretations experients apportion to their experiences. 
The findings generated from such work are likely to be of great interest to professionals, participants and the general public alike (Braud, 2004). For example, the idiographic, phenomenological approach taken in this research has highlighted the subtle affective, social and psychological mediating factors that influenced how the OB/NDE was interpreted and integrated during the course of daily life living. In order to more thoroughly understand the impact of these experiences it is important to consider how they fit within the biographical context of a person's life. In so doing, this approach has shown how concomitant physical and psychological events can interweave with an anomalous experience in multifarious ways. This in turn may assist or hinder how a person gets to the underlying meaning of their experience.

Our participants' initial OB/NDEs were unforeseen events. However, once they had occurred, they became fundamental constituents of their evolving self identities. Using IPA, we have been able to describe how participants initially cognitively appraised and then redefined their OB/NDEs, which involved moving from a period of initial confusion as to the causality of their experiences to later framing them as positive life-affirming occurrences. Participants then began a process of actively seeking out further information and support, and then, in some instances, they acted upon that information to try to further understand and bring meaning to their experiences. Related to this were the challenges our participant's faced in attempting to share their anomalous experiences with others and the various strategies they employed to manage this disclosure.

Furthermore, in keeping with its applied nature, by examining the experience and meaning of these life events, such research findings can better furnish psychologists and health care professionals to understand their clients' experiences and to help them with any potential personality transformations or psycho-spiritual crises that may arise after such anomalous events. 


\section{Notes}

${ }^{1}$ It is beyond the scope of this paper to consider this debate in any detail, but the interested reader may wish to consult Irwin and Watt (2007a) and Henry (2005) as useful starting guides to this discussion.

${ }^{2}$ Braud (2004) has criticised the use of the term "anomalous" as it may imply that a given experience may not be normal or natural, perhaps even automatically suggesting a pathology, i.e. abnormal. The authors would like to stress that our conception of "anomalous" is simply as a term referring to experiences that are infrequent and unusual, without any predilection to pathologising the experient. In our understanding, experients often report how normal their experiences feel to them and emphasize their positive, life-affirming aspects (Wilde \& Murray, 2009).

${ }^{3}$ Synchronicity: "[A] coincidence that is acausal, wherein certain events do not seem to be connected by normal causal means, and that is also particularly meaningful to the experiencer" (Hanson \& Klimo, 1998, p.281)

${ }^{4}$ Channeling: A phenomenon in which "a person purports to transmit information or messages directly from a personality or consciousness other than his or her own, usually through automatic writing or trance speaking; this other personality usually claims to be a nonphysical spirit or being” (Hastings, 1990, p. 99).

${ }^{5}$ A small sample size in a study will usually raise questions about the generalisability of the findings to wider populations. Whilst IPA is not opposed to more general claims for larger populations, it is "committed to the painstaking analysis of cases rather than jumping to generalizations" (Smith \& Osborn, 2008, p. 54). Although generalisable claims regarding a sample in a single IPA study are not made, as more studies with other samples are carried out with similar findings, more general claims become possible. Smith and Osborn (ibid) refer to this as 'theoretical generalisability', rather than 'empirical generalisability'. While we do not make any claims that the experiences described herein are universal to all OB/NDEs or OB/NDErs, we have explicated the meanings of the OB/NDE which emerged for our participants.

${ }^{6}$ Further themes extracted from the analysis of the data so far are currently in various stages of publication. A paper discussing the findings of the NDE group has been published (Wilde \& Murray, 2009). A second paper, focusing on the spontaneous group findings, Wilde \& Murray, "The experience and management of anomalous experience: An Examination of the Out-of-Body Experience Using Interpretative Phenomenological Analysis", is currently under review for Psychology and Psychotherapy: Theory, Research and Practice. A third paper based on the meditative group findings, Wilde \& Murray, “An Interpretative Phenomenological Analysis of 
Out-of-Body Experiences in Two Cases of Novice Meditators", has been submitted to the Australian Journal of

\section{Clinical and Experimental Hypnosis.}

${ }^{7}$ The brief discussion about embodiment herein naturally raises questions about the veridicality of OBEs. This is a hotly debated topic in psychology and parapsychology and one which currently resists explanation. What we are more interested in here is the interrelated role the body and the sense of being-in-the-world plays in our participants OBEs. The accounts of OBEs often contain reported content of altered perceptions that cannot be readily explained by the everyday functioning of a person's usual six senses-at least as is understood by classical philosophy. OBErs appear to have different perceptions regarding their body boundaries, which require further exploration and explanation. Studies in other fields investigating embodiment issues in people with disrupted body boundaries, for example, people with disabilities (see Murray and Sixsmith, 1999), have shown that, for some at people at least, the body boundary does not 'stop' at the skin surface, but is in fact much more acquiescent. Furthermore, as Langer (1989) notes, research has shown how the experience of a phantom limb is inextricably linked with the personal history of the experient, such that the limb can 'appear' when the experient reminisces about the time when the limb was lost, thus completing the intentional arc between the body-subject and the world.

\section{Acknowledgements}

This research was supported by the Bial Foundation, a Parapsychological Association Research Endowment, and also, in part, by a Faculty Scholarship Fund granted by the Faculty of Medical and Human Sciences at the University of Manchester. We would also like to express our gratitude to all. We would also like to thank the three reviewers for their constructive comments on an earlier draft of this paper. 


\section{References}

Alvarado, C. S. 1992: The Psychological Approach to Out-of-Body Experiences: A Review of Early and Modern Developments. Journal of Psychology 126(3), $237-250$.

Alvarado, C. S. 2000: Out-of-Body Experiences. In E. Cardeña, S. J. Lynn \& S. C. Krippner (Eds.), Varieties of Anomalous Experience: Examining the Scientific Evidence (pp. 183-218). Washington, DC: American Psychological Association.

Anderson, M. L. 2003: Embodied Cognition: A Field Guide. Artificial Intelligence $149,91-130$.

Atwater, P. M. H. 2003: The New Children and Near-Death Experiences. Rochester, Vermont: Bear \& Company.

Baltes, P. B., \& Danish, S. J. 1980: Intervention in Life Span Development and Aging: Issues and Concepts. In R. R. Turner \& H. W. Reese (Eds.), Lifespan Developmental Psychology Intervention (pp. 49-78). New York, NY: Academic Press.

Barrett, K. 1996: A Phenomenological Study of Channelling: The Experience of Transmitting Information from a Source Perceived as Paranormal.

Dissertation Abstracts International. RA12106 University Microfilms No. LD03475:

Bem, D. J., \& Honorton, C. 1994: Does Psi Exist? Replicable Evidence for an Anomalous Process of Information Transfer. Psychological Bulletin 115, 4-18.

Blackmore, S. J. 1984: A Psychological Theory of the Out-of-Body Experience. Journal of Parapsychology, 48, 201-218. 
Blackmore, S. J. 1986: Spontaneous and Deliberate OBEs: A Questionnaire Survey. Journal of the Society for Psychical Research 53(802), 218-224.

Braud, W. 1993: Honoring Our Natural Experiences. Journal of the American Society for Psychical Research 88(3), 293-308.

Braud, W. 2004: The Farther Reaches of Psi Research: Future Choices and Possibilities. In M. A. Thalbourne, L. Storm \& B. D. Josephson (Eds.), Parapsychology in the Twenty-First Century: Essays on the Future of Psychical Research (pp. 38-62). Jefferson, NC: McFarland \& Co. Inc.

Brocki, J. M., \& Wearden, A. J. 2006: A Critical Evaluation of the Use of Interpretative Phenomenological Analysis (IPA) in Health Psychology. Psychology \& Health 21(1), 87-108.

Brown, S. V., \& White, R. A. 1997: Triggers, Concomitants, and After Effects of EHEs: An Exploratory Study. Exceptional Human Experience 15(1), 150-156.

Bruner, J. 1990: Acts of Meaning. Cambridge, MA: Harvard University Press.

Cardeña, E. 1988: The Phenomenology of Quiescent and Physically Active Deep Hypnosis. Paper presented at the 39th Annual Meeting of the Society for Clinical and Experimental Hypnosis, Asheville, NC.

Cardeña, E., Lynn, S. J., \& Krippner, S. 2000: Varieties of Anomalous Experience: Examining the Scientific Evidence. Washington, DC: American Psychological Association.

Castro, M. 2005: “Oooh...that's a bit weird”: Attempting to Rationalise the Irrational and Explain the Unexplainable. London: Goldsmiths College, University of London. 
Chin, J. T., Hayward, M., \& Drinnan, A. 2009: 'Relating' to Voices: Exploring the Relevance of this Concept to People Who Hear Voices. Psychology and Psychotherapy: Theory, Research and Practice 82, 1-17.

Conrad, P. 1987: The Experience of Illness: Recent and New Directions. Research in the Sociology of Healthcare 6, 1-31.

Corbett, L. 1996: The Religious Function of the Psyche. London, England: Routledge.

Csordas, T. J. 1993: Somatic Modes of Attention. Cultural Anthropology 8(2), 135156.

Davidson, R. J., Goleman, D. J., \& Schwartz, G. E. 1984: Concomitants of Meditation: A Cross-Sectional Study. In D. H. Shapiro \& R. N. Walsh (Eds.), Meditation: Classic and Contemporary Perspectives. Berlin: Transaction Publishers.

Dinos, S., Stevens, S., Serfaty, M., Weich, S., \& King, M. 2004: Stigma: The Feelings and Experiences of 46 People with Mental Illness. British Journal of Psychiatry 184, 176-181.

Dougherty, C. M. 1990: The Near-Death Experience as a Major Life Transition. Holistic Nursing Practice 4(3), 84-90.

Druckman, D., \& Swets, J. A. 1988: Enhancing Human Performance. Issues, Theories, and Techniques. Washington, DC: National Academy Press.

Finlay, L., \& Langdridge, D. 2006: Embodiment. In W. Hollway, H. Lucey \& A. Phoenix (Eds.), Social Psychology Matters. Maidenhead: Open University Press.

Flowers, P., Smith, J. A., Sheeran, P., \& Beail, N. 1997: Health and Romance: Understanding Unprotected Sex in Relationships between Gay Men. British Journal of Health Psychology 2, 73-86. 
Greyson, B. 1994: Near-Death Experiences. In R. Corsini (Ed.), The Encyclopedia of Psychology (pp. 460-462). New York: Wiley.

Greyson, B. 2000: Near-Death Experiences. In E. Cardeña, S. J. Lynn \& S. C. Krippner (Eds.), Varieties of Anomalous Experience: Examining the Scientific Evidence (pp. 315-352). Washington, DC: American Psychological Association.

Greyson, B., \& Bush, N. E. 1992: Distressing Near-Death Experiences. Psychiatry 55, 95-110.

Gow, K., Lang, T., \& Chant, D. 2004: Fantasy Proneness, Paranormal Beliefs and Personality Features in Out-of-Body Experiences. Contemporary Hypnosis 21(3), 107-125.

Hall, E. T. 1969: The Hidden Dimension. Garden City, NY: Anchor Books.

Hanson, D., \& Klimo, J. 1998: Toward a Phenomenology of Synchronicity. In R. Valle (Ed.), Phenomenological Inquiry in Psychology: Existential and Transpersonal Dimensions (pp. 281-307). New York: Plenum Press.

Hastings, A. 1990: Psi and the Phenomena of Channeling. In L. A. Henkel \& J. Palmer (Eds.), Research in Parapsychology (pp. 99-123). Metuchen, NJ: Scarecrow Press.

Heath, P. R. 1999: Into the Psychokinetic (PK) Zone: A Phenomenological Study of the Experience of Performing PK. Journal of Parapsychology 63, 205-206.

Heath, P. R. 2000: The PK Zone: A Phenomenological Study. Journal of Parapsychology 64, 53-72.

Henry, J. (Ed.) 2005: Parapsychology: Research on Exceptional Experiences. London: Routledge. 
Hoelzel, B., \& Ott, U. 2006: Relationships between Meditation Depth, Absorption, Meditation Practice, and Mindfulness: A Latent Variable Approach. Journal of Transpersonal Psychology 38(2), 179-199.

Husserl, E. 1931: Ideas: General Introduction to Pure Phenomenology, Volume 1. New York, NY: Macmillan.

Inglis, B. 1992: Natural and Supernatural: A History of the Paranormal from Earliest Times to 1914 (Rev. Ed.). Dorset: Prism Press.

Irwin, H. J. 2000: The Disembodied Self: An Empirical Study of Dissociation and the Out-of-Body Experience. Journal of Parapsychology 64, 261-277.

Irwin, H. J., \& Watt, C. 2007a: Introduction. In An Introduction to Parapsychology (5th Rev. Ed., pp.1-10). Jefferson, NC: McFarland \& Co Inc.

Irwin, H. J., \& Watt, C. 2007b: Out-of-Body Experiences. In An Introduction to Parapsychology (5th Rev. Ed., pp. 173-191). Jefferson, NC: McFarland \& Co Inc.

Kennedy, J. E., \& Kanthamani, H. 1995: An Exploratory Study of the Effects of Paranormal and Spiritual Experience on People's Lives and Well-Being. Journal of the American Society for Psychical Research 89, 249-264.

Kohr, R. L. 1980: A Survey of Psi Experiences among Members of a Special Population. Journal of the American Society for Psychical Research 74, 395411.

Langdridge, D. 2007: Phenomenological Psychology: Theory, Research and Method. London: Pearson Prentice Hall.

Langer, M. M. 1989: Merleau-Ponty's Phenomenology of Perception: A Guide and Commentary. London: Palgrave Macmillan. 
Mauss, M. 1950: Les Techniques du Corps. In Sociologie et Anthropologie. Paris: Presses Universitares de France.

Merleau-Ponty, M. 1962: Phenomenology of Perception. London and New York: Routledge \& Kegan Paul.

Moody, R. A. 1975: Life after Life. Covington, GA: Mockingbird Books.

Monroe, R. 1971: Journeys Out of the Body. New York: Doubleday.

Murray, C. D., \& Fox, J. 2005: Dissociational Body Experiences: Differences between Respondents with and without Prior Out-of-Body Experiences. British Journal of Psychology 96, 441-456.

Murray, C. D., Fox, J., \& Wilde, D. 2006: Poster presentation: "Investigating the Multidimensional Nature of Body Image, Sensorial Representation and Phenomenology in Relation to Different Forms of Out-of-body Experience". 6th Bial symposium: Behind and Beyond the Brain. Porto, Portugal.

Murray, C. D., \& Sixsmith, J. 1999: The Corporeal Body in Virtual Reality. Ethos 27(3), 315-343.

Myers, S. A., Austrin, H. R., Grisso, J. T., \& Nickeson, R. C. 1983: Personality Characteristics as Related to the Out-of-Body Experience. Journal of Parapsychology 47, 131-144.

Palmer, J. 1978: The Out-of-the Body Experience: A Psychological Theory. Parapsychology Review 95, 19-22.

Palmer, G., \& Braud, W. 2002: Exceptional Human Experiences, Disclosure, and a More Inclusive View of Physical, Psychological, and Spiritual Well-Being. Journal of Transpersonal Psychology 34, 29-61.

Palmer, J., Honorton, C., \& Utts, J. 1988: Reply to the National Research Council Study on Parapsychology: A Special Report Prepared for the Board of 
Directors of the Parapsychological Association, Inc. North Carolina:

Parapsychological Association, Inc.

Rawciffe, D. H. 1959: Illusions and Delusions of the Supernatural and the Occult. New York: Dover.

Reed, H. 1995: Close Encounters in the Liminal Zone Part I: Studies in Imaginal Communication. Journal of Analytical Psychology 41(1), 81-116.

Reed, H. 1996: Close Encounters in the Liminal Zone: Experiments in Imaginal Communication Part II. Journal of Analytical Psychology 41(2), 203-226.

Reid, K., Flowers, P., \& Larkin, M. 2005: Interpretative Phenomenological Analysis: An Overview and Methodological Review. The Psychologist 18, 20-23.

Ring, K. 1980: Life at Death: A Scientific Investigation of the Near-Death Experience. New York: Coward, McCann \& Geoghegan.

Ring, K. 1993: The Near-Death Experience. In R. Walsh \& F. Vaughan (Eds.), Paths Beyond Ego: The Transpersonal Vision (pp. 195-202). New York: Tarcher/Putnam.

Smith, J. A. 1996: Beyond the Divide between Cognition and Discourse: Using Interpretative Phenomenological Analysis in Health Psychology. Psychology and Health 11, 261-271.

Smith, J. A. 1999: Identity Development During the Transition to Motherhood: An Interpretative Phenomenological Analysis. Journal of Reproductive and Infant Psychology 17, 281-300.

Smith, J. A., \& Eatough, V. 2006: Interpretative Phenomenological Analysis. In G. M. Breakwell, S. Hammond, C. Fife-Schaw \& J. A. Smith (Eds.), Research Methods in Psychology (3rd Ed., pp. 322-341). London, Thousand Oaks, New Delhi: Sage. 
Smith, J. A., Flowers, P., \& Larkin, M. 2009: Interpretative Phenomenological Analysis: Theory, Method and Research. London: Sage.

Smith, J. A., Jarman, M., \& Osborn, M. 1999: Doing Interpretative Phenomenological Analysis. In M. Murray \& K. Chamberlain (Eds.), Qualitative Health Psychology: Theories and Methods (pp. 218-240). London: Sage.

Smith, J. A., \& Osborn, M. 2003: Interpretative Phenomenological Analysis. In J. A. Smith (Ed.), Qualitative Psychology: A Practical Guide to Research Methods. London: Sage.

Smith, J. A., \& Osborn, M. 2008: Interpretative Phenomenological Analysis. In J. A. Smith (Ed.), Qualitative Psychology. A Practical Guide to Research Methods (pp. 51-80). London: Sage.

Storey, L. 2007: Doing Interpretative Phenomenological Analysis. In E. Lyons \& A. Coyle (Eds.), Analysing Qualitative Data in Psychology (pp. 51-64). London: Sage.

Tart, C. T. 1971: On Being Stoned: A Psychological Study of Marijuana Intoxication. Palo Alto, CA: Science \& Behaviour Books.

Tobacyk, J. J., \& Mitchell, T. P. 1987: The Out-of-Body Experience and Personality Adjustment. Journal of Nervous and Mental Disease 175(6), 367-370.

Valle, R. S. 1998: Transpersonal Awareness: Implications for Phenomenological Research. In R. S. Valle (Ed.), Phenomenological Inquiry in Psychology: Existential and Transpersonal Dimensions (pp.271-279). New York: Plenum.

Vignoles, V. L., Chryssochoou, X., \& Breakwell, G. M. 2004: Combining Individuality and Relatedness: Representations of the Person among the Anglican Clergy. British Journal of Social Psychology 43, 113-132. 
Walker, B. A., \& Serdahely, W. J. 1990: Historical Perspectives on Near-Death Phenomena. Journal of Near-Death Studies 9(2), 105-121.

White, R. A. 1997: Dissociation, Narrative, and Exceptional Human Experience. In S. Krippner \& S. Powers (Eds.), Broken Images, Broken Selves: Dissociative Narratives in Clinical Practice (pp. 88-121). Washington, DC: BrunnerMazel.

Wilde, D., \& Murray, C. D. 2009: The Evolving Self: Finding Meaning in Near-Death Experiences Using Interpretative Phenomenological Analysis. Mental Health, Religion \& Culture 12(3), 223-239.

Willig, C. 2001: Introducing Qualitative Research in Psychology: Adventures in Theory and Method. Maidenhead, UK: Open University Press.

Wooffitt, R. 1992: Telling Tales of the Unexpected: The Organisation of Factual Discourse. Hemel Hempstead: Harvester Wheatsheaf. 